\title{
Study on Development Prediction and Evaluation Model of New Energy Wind Power
}

\author{
Yanli $\mathrm{Hu}^{1,}$, Jun Liang ${ }^{2, b}$ \\ ${ }^{1}$ School of Politics and Public Administration of Xinjiang University \\ ${ }^{2}$ TBEA Sunoasis co., LTD \\ aLuckyhyl@126.com, ${ }^{\mathrm{b}} 19671582 @ q q . c o m$
}

Keywords: new energy; wind power development; forecasting; evaluation model

\begin{abstract}
In the 21st century, energy demand has become a global problem, China's wind power energy jumps forward from start to large-scale development and its use also shows the characteristic of diversified development and thus requires the research of its related technology and personnel to ensure that the new energy wind power industry can further develop healthily. Based on this, this paper study from research on the development prediction and evaluation model of new energy wind power.

The continued development of new energy wind power industry, on one hand, has a higher requirement of technology and needs some technically sophisticated technical personnel, on the other hand, the continuous improvement of technology level is bound to promote the continuous development of the biotechnology industry. So according to the current new wind energy development needs, study, evaluate and forecast new energy technologies talent demand and skill progress levels, which has extremely important practical significance for the development of new energy wind power.
\end{abstract}

\section{Study on the development prediction and evaluation model of wind power energy}

The continuous and scientific development of new energy wind power industry is in line with the country's current energy needs, and stable development of new energy wind power industry requires sustainable wind power talent supply and excellent wind and power industry structure. The forecasting and evaluation model of new energy wind and power model development should be from the following aspects:

\section{Construction and forecast from technical point of view}

On the analysis of new energy wind and power technology development and trend, you can build new energy wind and power industry technologies evaluation model and build model based on analytic methods. Through a series of model construction, some targeted technology development direction can be found, which can increase targets in personnel training.

Installed capacity

Installed capacity of new energy wind power industry development can be forecast-ed by gray theory. The construction of the model can provide some data reference for national reasonable plan of wind and power industry and the healthy development.

\section{Forecast and evaluation of wind and power generator load}

For new energy power industry wind power load forecasting model, three models-gray prediction model, Markov model and time series forecasting model can be organically combined[3] and constructed wind and power generation load forecasting model from the aspects of the best group. By constructing this model, it is possible to obtain a good prediction effect, which can provide some reference support for power scheduling and power planning. In addition, wind and power load forecasting model also has a certain reference value for load forecasting of other new energy sources. 


\section{Wind industry Personnel structure prediction model}

By personnel structure cluster analysis model, and then make the professional segments as the starting point to effectively sort personnel structure complication caused by complex and multidisciplinary of the wind power industry professional and can further analyze new energy industrial technology personnel structure using a multi-dimensional approach, which effectively strengthens targeted personnel structure prediction and make the development direction of the wind power industry more clearly. The effects of it were obvious in the promotion of new energy talent agencies analysis, shown as Figure 1 is a art frames of new energy wind power development requirements for technical personnel .

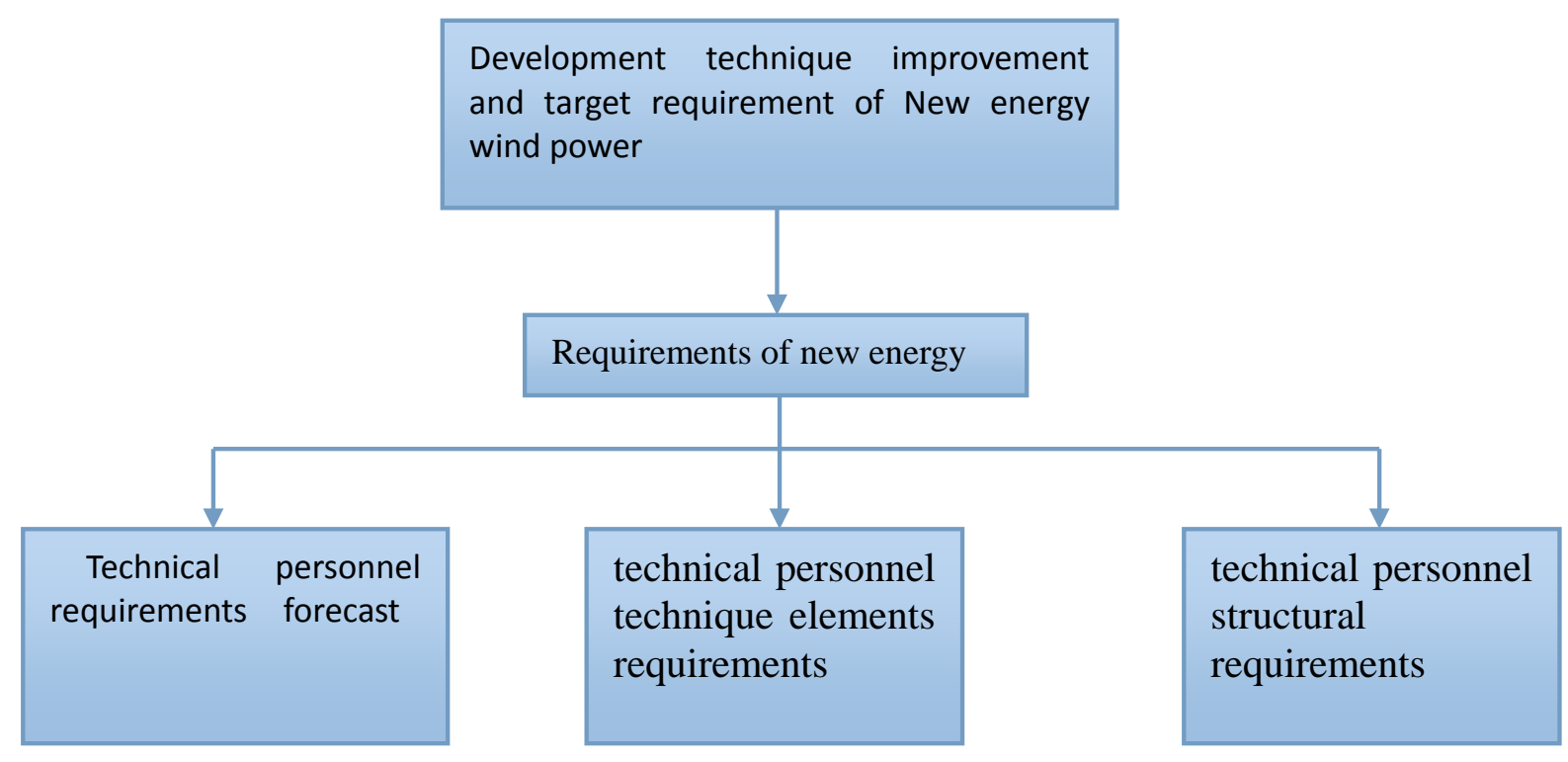

Figure 1 Requirements of new energy development for technical personnel frame diagram

\section{Talent supply forecast}

By neural network optimization and Markov chain technology talent supply forecasting model, provide some theoretical support for new energy wind industry technical personnel.

\section{Proposals for new energy wind and power development}

By wind and power prediction and evaluation technical personnel supply and demand forecasts, electricity load forecasting and prediction of wind and power capacity, next provide some suggestions from institution construction and new energy wind and power development.

Proposals on new energy wind and power development system construction

1) Pay attention to planning and management of wind and power industry

The root cause of current new energy wind power industry low efficiency, the too fast developing pace and difficult connection lies in dispersed management functions of government in the new energy wind power development, which results in a large number of resource waste and unplanned development in new energy wind power development. So you must pay attention to the following two aspects: (1) must develop scientific and long-term plan from the perspective of the whole country and emphasize institution of plan. (2) Make plan as the core guidance and strengthen wind and power development plan management [2].

2) Pay attention to government policy support

Development of foreign new energy sources is mostly led by government and the government will give policy support in many areas, while though the current development of China's new energy is supported by a range of policy, but there still appear some problems in terms of policy 
implementation and specific utilization of new energy sources. To solve these problems, firstly we should construct a scientific and effective wind power development appraisal system; secondly further improve related norms and regulations of wind power development ; and the third should do the implementation of wind power development subsidy system; and finally also should do better in multi-mechanism joint work.

3) Construction of a scientific and effective goals evaluation system

Organized by the national energy-related sector and actively play a role of local government, ex plicit wind and power development requirements and objectives of various regions, such as wind an d power development industrial system, wind and power scale, the specific growth rate, etc. to impr ove wind and power industry tracking management efforts to achieve dynamic adjustment and regul arly disclosed and establish a scientific and effective information disclosure system to actively recei ve community supervision.

\section{4) Multi-mechanism interaction}

Must strengthen the positive incentive requirements. Firstly, regular wind and power project dev elopment proportion and make grid electricity as assessment indicators. Secondly, continuously reg ular power grid companies wind and power quota to improve the level of the entire power grid tech nology, construct wind and power online scheduling rules and block area market, ultimately effectiv ely improve grid wind and power bearing assimilative capacity. It also requires the establishment of some effective incentives to guide and encourage the development of green power grid enterprises i nfluence. Ultimately promote green power grid construction under government guidance, guide and resolve the current wind and power consumption problem.

\section{New energy wind power development talents training proposals}

The description and related research indicate that currently China's wind and power high-end technical talent exists great gap, which is caused by many reasons, such as leaps and bounds development of wind power industry, the wind power industry belonging to high-tech industry, the long personnel training period and so on, and new energy personnel training should focus on the following points:

1) Further improve the policy environment of outside personnel training

For this regard, firstly should further support related professionals in Research Institute and University, academic settings, and work-related education. Secondly related financial sector must provide some special funds for the development of new energy wind power personnel training. Finally personnel training system should be optimized to make the current personnel training system developing toward cultivating talent transformation.

2) improve the personnel management system

The talent gap, on one hand, is due to the lack of personnel training, while on the other hand it is because of a big flaw talent management system. So to improve personnel management system is necessary. The specific implementation is that firstly enterprise talent management should be based on job requirements; secondly improve and optimize the relevance and systemic of personnel management system. Finally, it should strengthen update and maintain the system.

\section{Reform}

At present, China's wind power system has been reformed many times, but there are still market monopoly, the establish of electricity market is still difficulties, and these problems are mainly as follows: (1) monopoly in the wind power market seriously restricts the healthy development of the electricity market; (2) regional electricity market is not well established, the distribution is difficult to separate, which makes the new energy receiving capacity is clearly insufficient in the grid; (3) the power of supervision is insufficient, the role of government in market regulation is not well highlighted. Based on these problems, China's electric power system reform must first ask the government to vigorously promote, clarify related goals, break the traditional monopoly, import competition in the market system, and ultimately construct safe, economical, efficient and high-quality electricity market; and further coordinate to optimize the electricity market resources allocation, promote the separation of power transmission and distribution market, and other independent reform; also should strengthen supervision, strengthen institutional guarantees, and 
ultimately through mechanisms and institutional innovation to achieve rapid and healthy development of China's wind power industry.

\section{Conclusion}

All in all, the study for new energy wind and power development forecasting and evaluation model plays an important role for continuous and healthy development of new energy wind power industry. This article focuses on the description of some forecasting methods and gives some suggestion in the development of wind power industry. However, due to the limitations of space herein and the ability of collecting information. It is still inadequate in some places as described herein and we hope that the scholars give correction.

\section{References}

[1] Zhu Xiaofeng, Zhu Xiaojin.. The Forecasting Method and Analysis based on Gray System Theory [J]. Nantong University (Natural Science 2005), (30) 45-46.

[2] He Yonggui, Han Yue'e, Yang Shijun, Zhang Zhengang. The Preference of Human Resource Demand Forecasting Model [J]. North China Electric Power University, 2005 (6), 80-83.

[3] Chi Benkun. Research on International Cooperation Issues of New Energy CDM Projects under the Perspective of the Low Carbon Economy. Jilin University, 2011.

[4] Wang Shaohua. Study on China's Energy Structure Optimization Based on the Low-carbon Economy[D]. Harbin Engineering University, 2013.

[5] Sun Yiqing. Study on CGE Models Construction of Wind and Power Industry Policy Analysis and Its Application[D]. Nanjing Aeronautics and Astronautics University, 2012. 